\title{
Microcracking of High Performance Concrete Subjected to Biaxial Tension - Compression Stresses
}

\author{
José Marcio F. Calixto \\ Departamento de Estruturas - Escola de Engenharia - UFMG \\ Av. Contorno, 842, 2ำ andar, 30110-060 Belo Horizonte - MG, Brazil
}

Received: September 27, 2001; Revised: July 10, 2002

\begin{abstract}
The results of an experimental investigation on the microcracking of high-performance concrete subjected to biaxial tension-compression stresses are presented. Short-term static tests and microcracking mapping were performed on $12.5 \mathrm{~cm}$ square by $1.25 \mathrm{~cm}$ thick plates. Strain controlled tests were executed in a biaxial testing machine constructed at the University of Texas. The primary variables studied were the deformations and the ultimate stress level at each stress ratio as well as the microcracking patterns and total crack lengths. For the microcracking study, the plates, after straining, were impregnated by an epoxy and then examined under a microscope. Microcracks were classified into simple and combined cracks, since this distinction allows for a much better representation of the microcracking process. A simple crack is either a bond or mortar crack where a combined crack contains both of these. For all stress ratios tested, the stress-strain behavior was directly related to the internal microcracking pattern. In all cases, the failure was directly related to the formation and propagation of the combined cracks.
\end{abstract}

Keywords: high performance concrete, microcracking, biaxial stresses

\section{Introduction}

Concrete in normal conditions is a versatile, resistant and durable construction material. However under several physical and chemical processes as well as certain environmental conditions it may deteriorate in a short period of time. This fact has led researchers in the last 30 years to develop the high-performance concrete. High-performance concrete (HPC) is a concrete which possess high workability, high strength and low permeability.

In most strucutures, concrete is often subjected to biaxial states of stress, and the behavior of the material under these types of loadings must be well understood. It is therefore not surprising that numerous investigations into the behavior and strength of normal strength concrete (NSC) under biaxial stresses have been done in the past 40 years. On the other hand, HPC differs from NSC in several aspects $^{1}$ and these differences must be better understood to facilitate the design and construction of more structures with HPC.

Since the beginning of last century, research has shown the existence of microcracks in concrete. However, only since the 1960's have these microcracks been observed, characterized and measured. The development of fracture mechanics models, during the last 30 years, enabled the structure of concrete to be taken into consideration. This fact has led to the increasingly application of fracture mechanics in the design of concrete elements ${ }^{2}$. In spite of this, the theory of fracture mechanics in concrete is not yet as mature as continuum theories ${ }^{3}$, such as elasticity and viscoelasticity. This is in part due to the limited understanding of the formation and propagation of microcracks in concrete.

Thus the aim of this paper is to gain further understanding on the behavior and failure mechanism of HPC when subjected to biaxial stresses in terms of internal microcracking. Short-term static tests and microcracking mapping were performed on $12.5 \mathrm{~cm}$ square by $1.25 \mathrm{~cm}$ thick plates subjected to biaxial tension-compression stresses at selected stress ratios. Strain controlled tests were executed in a biaxial testing machine constructed at the University of Texas. The internal microcracking patterns observed at different stress-ratios and load levels were related to the failure modes corresponding to that stress-ratio. 


\section{Materials and Experimental Procedures}

Materials

The proportioning of the components for HPC mixes is more critical than for normal concrete since for HPC optimum performance is required from each component used. For the current investigation, the materials used included Brazilian Type CP I cement, crushed limestone, with a maximum size of $1.25 \mathrm{~cm}$, as coarse aggregate and a river sand as fine aggregate. For the necessary slump the superplasticizer employed was Pozzolith 400-N manufactured by Master Builders of Cleveland, Ohio. The mix design consisted of $575 \mathrm{~kg}$ of cement per cubic meter of concrete, a water/cement ratio (by weight) of 0.28 , a aggregate/cement ratio of 2.88 and a coarse-to-fine aggregate ratio of 1.72. The superplasticizer/cement ratio (by weight) was 0.013 .

A total of six $15 \mathrm{~cm} \times 15 \mathrm{~cm} \times 50 \mathrm{~cm}$ beams were cast using steel molds. A pencil vibrator was used for compaction of the concrete into the molds. The newly cast molds were covered with a wet burlap for 24 hours. The beams were then removed from the molds and placed in a curing room at a temperature of $22 \pm 2{ }^{\circ} \mathrm{C}$ and 95 to 100 percent relative humidity.

\section{Specimen Preparation}

The preparation of the plate specimens started with the cutting of the $12.5 \mathrm{~cm}$ square by $1.25 \mathrm{~cm}$ thick plates from the beams. This process was initiated after at least 56 days of casting and was performed using a slow-feeding diamond blade lapidary saw. For the $1.25 \mathrm{~cm}$ dimension, the plates were sliced slightly larger than needed and ground down employing a vibrating lapidary table. After grinding, the specimens were again stored in the curing room. At least three days prior to testing, each specimen was removed from the curing room for preparation of the loading edges. The edges were sand-blasted with fine silica sand to roughen the surfaces, facilitating a good bond between the edges of the specimen and the epoxy adhesive.

For the transmission of the tensile forces, the edges of the specimen must be securely attached to the comb-platens and the binding material used must develop a sufficient strong bond with both the concrete and the aluminum to withstand the maximum tensile force expected. The exposed edges of the specimen were then coated with a thin layer of Adhesive Engineering Company 1411 Non Sag Paste Adhesive. The mating surfaces of the comb-platens and the specimen were then pressed together an allowed to cure for 36 hours.

\section{Loading Apparatus and Testing Procedure}

The loading apparatus used was a special biaxial testing machine built at The University of Texas. It consists of steel framing members, hydraulic rams and load cells. Each ram was controlled by an electronic hydraulic servo system. In order to prevent any significant confining stress, special steel brush-bearing platens were used for compressive loads. They were of a design similar to those employed by Hilsdorf ${ }^{4}$. For the tensile loads, a different set of platens, made of a single aluminum plate, was used.

Instrumentation was necessary to measure and record loads and strains. Load cells were employed for measuring the loads, while strain gages were used for evaluation of the deformations. Two strain gages, glued on opposite faces of which specimen were used. The rate of loading was conditioned to match the strain gage feedback signal by the electronic hydraulic servo system.

Seven specimens were tested for each principal stress ratio. The first three were used to establish the deformations and strength. Subsequently, two were loaded to about $70 \%$ of the strength, and the last two to loads above that point but prior to failure. These last four specimens were used in the microcracking study. The principal stress-ratios used were $\sigma_{2} / \sigma_{1}=0$ (uniaxial compression); $\sigma_{2} / \sigma_{1}=-0.5$ and -1.0 for biaxial tension-compression; and $\sigma_{2} / \sigma_{1}=\infty$ for uniaxial tension.

\section{Microcracking Study}

Several methods have been used to study the microcracking of concrete, including acoustic emission ${ }^{5}$, microscope technique with dye ${ }^{6}$, and computerized tomography analysis ${ }^{7}$. According to Nemati et al. ${ }^{8}$, most techniques have limited capability in representing the geometry and state of microcracks as they exist under load specially when concrete is subjected to tensile stresses. Since in this study, concrete was not only subjected to tensile stresses but also to a biaxial state of stresses, the selected technique consisted of microscope examination of strained specimens after the injection of a blue dye epoxy under pressure $(0.15 \mathrm{MPa})$ 9 . The epoxy used was composed of a blue dye, a resin (Shell $\mathrm{R}$ 828), ether and a hardener. The injection process consisted of pouring the epoxy into a tray with several specimens so that it flowed up and around each specimen. The tray was then put into a chamber and the pressure was applied. The impregnation required about $2 \mathrm{~h}$.

The microcracks were mapped, using a fine tip black ink pen, on a photograph taken of each cell of a $3 \times 3$ mesh drawn on the face of each specimen. The stereomicroscope used was Zeiss (model SM 350/50X) with a 50X maximum magnification. A magnetic digitizing table was used to automatically compute the $\mathrm{x}-\mathrm{y}$ coordinates of any point along a crack. This digitizing table was connected to a VAX computer each stored automatically the coordinates into a file. A program was then used to compute the length of each crack. 


\section{Test Results and Analysis}

\section{General Behavior}

Typical stress-strain curves at different principal stress ratio tested are shown in Fig. 1. It is interesting to note that only for the case of uniaxial compression, the stress-strain curve deviates significantly from linearity at high levles of straining. This behavior is directly related to the observed internal microcracking process and will be explained in the next section. The analysis of the plots also indicate that the ultimate compressive strength under biaxial tension-compression is significantly less than the uniaxial compressive strength.

With respect to the deformations, the results show that the introduction of a principal tensile stress reduces significantly the magnitude of the tensile strain at failure. This indicates that high-performance concrete as normal strength concrete can sustain a larger amount of indirect tensile strain, due to Poisson's effect, than direct tensile strains.

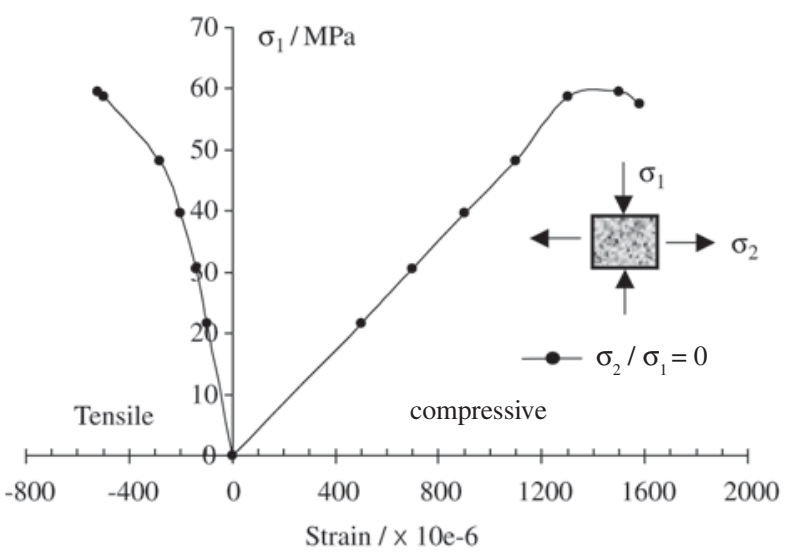

(a) Stress-Strain Relationship in Uniaxial Compression

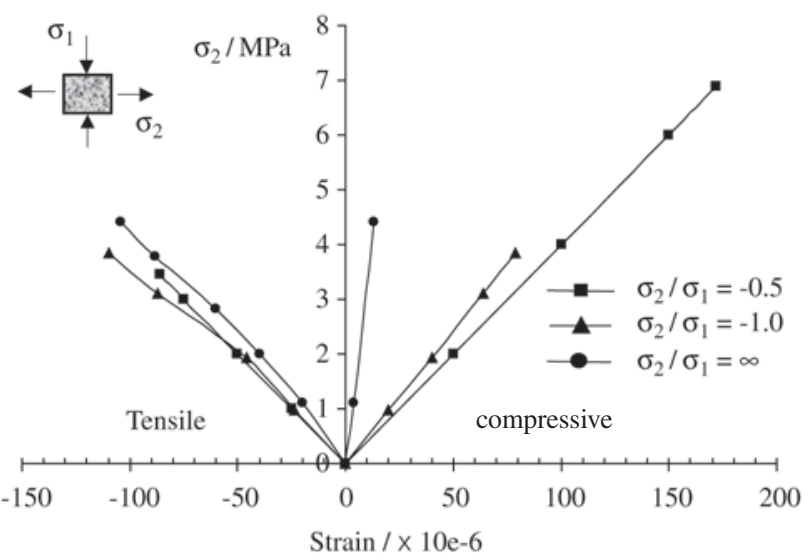

(b) Stress-Strain Relationships at Different Stress Ratios

Figure 1. Stress-Strain Relationships at Different Stress Ratios.
The biaxial tension-compression strength envelope is shown in Fig. 2. The strength envelope for normal strength concrete, obtained by Tasuji et al. ${ }^{10}$, is also shown. The data presented in the plot are normalized with respect to the plate uniaxial compressive strength. The shape of the strength envelope for biaxial tension-compression of HPC is much more linear than that obtained for normal strength concrete under similar loading conditions. The comparison also indicates that the biaxial tension-compression strength is different for different strength concretes. Under biaxial tension-compression, the decrease in the compressive strength is lower for concretes with a normal uniaxial compressive strength (NSC), and is higher for concretes having a higher uniaxial compressive strength (HPC). This difference in behavior has important implications on the design of HPC structures. An example would be in the shear design of reinforced concrete flexural elements. Since biaxial tensioncompression stresses exist in the shear region of these elements, the stresses corresponding to the formation of the diagonal cracks should be more carefully determined when HPC is used.

The failure mode of all plate specimens tested fell into one category, tensile splitting in a plane or planes perpendicular to the direction of the principal tensile strain. The failure surface contained fractures through both mortar and coarse aggregate. These results suggest that the failure criterion for high-performance concrete under biaxial stresses is a limiting value for the tensile strain. It must be realized that the value of the tensile strain is not constant: it is dependent upon the applied state of stress.

\section{Microcracking Analysis}

The original data from the microcracking study consisted of close-up pictures of each one of the nine squares drawn on the face of each specimen tested. A representative pic-

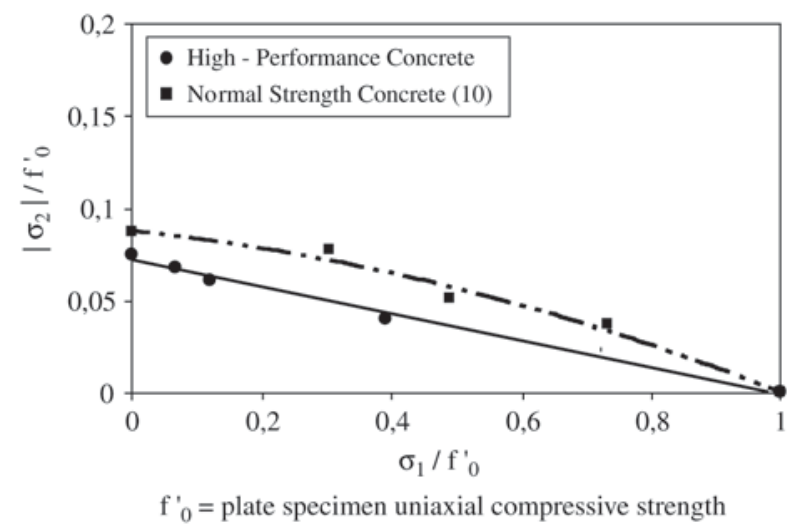

Figure 2. Strength Envelope of Concrete under Biaxial TensionCompression Stresses. 
Table 1. Microcracking Analysis.

\begin{tabular}{|c|c|c|c|c|c|}
\hline \multirow[t]{2}{*}{ Stress Ratio } & \multirow[t]{2}{*}{$\frac{\text { Applied Stress }}{\text { Strength }^{1}}$} & \multicolumn{2}{|c|}{ Simple Crack Ratio } & \multicolumn{2}{|c|}{ Combined Crack Ratio } \\
\hline & & Bond Crack ${ }^{2}$ & Mortar $\mathrm{Crack}^{3}$ & Type I crack ${ }^{4}$ & Type II crack $^{5}$ \\
\hline Unloaded Specimen & 0 & 0.47 & 0.53 & 0 & 0 \\
\hline Uniaxial & 0.68 & 0.02 & 0.43 & 0.44 & 0.11 \\
\hline Compression & 0.91 & 0 & 0.26 & 0.50 & 0.24 \\
\hline \multirow[t]{2}{*}{-0.5} & 0.68 & 0.04 & 0.34 & 0.44 & 0.18 \\
\hline & 0.89 & 0 & 0.35 & 0.45 & 0.20 \\
\hline \multirow[t]{2}{*}{-1.0} & 0.65 & 0.01 & 0.45 & 0.34 & 0.20 \\
\hline & 0.87 & 0 & 0.41 & 0.38 & 0.21 \\
\hline Uniaxial & 0.72 & 0 & 0.45 & 0.36 & 0.19 \\
\hline Tension & 0.95 & 0 & 0.42 & 0.38 & 0.20 \\
\hline
\end{tabular}

${ }^{1}$ Ratio between the applied stress and the strength corresponded to that stress-ratio; ${ }^{2}$ Ratio between the total length of bond cracks and the total length of cracks; ${ }^{3}$ Ratio between the total length of mortar cracks and the total length of cracks; ${ }^{4}$ Ratio between the total length of Type I combined cracks and the total length of cracks; ${ }^{5}$ Ratio between the total length of Type II combined cracks and the total length of cracks.

ture of the crack pattern observed in one of the squares is shown in Fig. 3.

The microcracking results, shown in Table 1, are presented in terms of simple (bond or mortar) and combined cracks which, according to Carrasquillo et al. ${ }^{11}$, represent much better the microcracking process taking place in highperformance concrete. A simple crack was considered to be a single bond or mortar crack not connected to another crack. A combined crack contained two or more cracks connected to each other. One further division of combined cracks into Type I and II was made to obtain an indication of the extent and stability of progressive cracking. A Type I combined crack consisted of a combination of one bond crack and one mortar crack or of a combination two bond cracks connected by a mortar crack. A Type II combined crack consisted of a combination of at least two bond cracks and two mortar cracks. A Type I combined crack was also considered a stable crack.

The existence of cracks in concrete prior to loading is well documented ${ }^{3,6,11}$. In NSC, bond cracks usually form around the large coarse aggregate particles, since the aggregate-mortar interface is the weakest link in the system. In HPC this is no longer true. Table 1 shows that the percentage of bond cracks ratio is almost equal to the the percentage of mortar cracks. This is due to a stronger transition zone which results from the reduction of excess bleeding, and a better compatibility of strength and elastic properties between the coarse aggregate and the mortar.

In uniaxial compression, the analysis of the microcracking process indicates a significant percentile change in the total

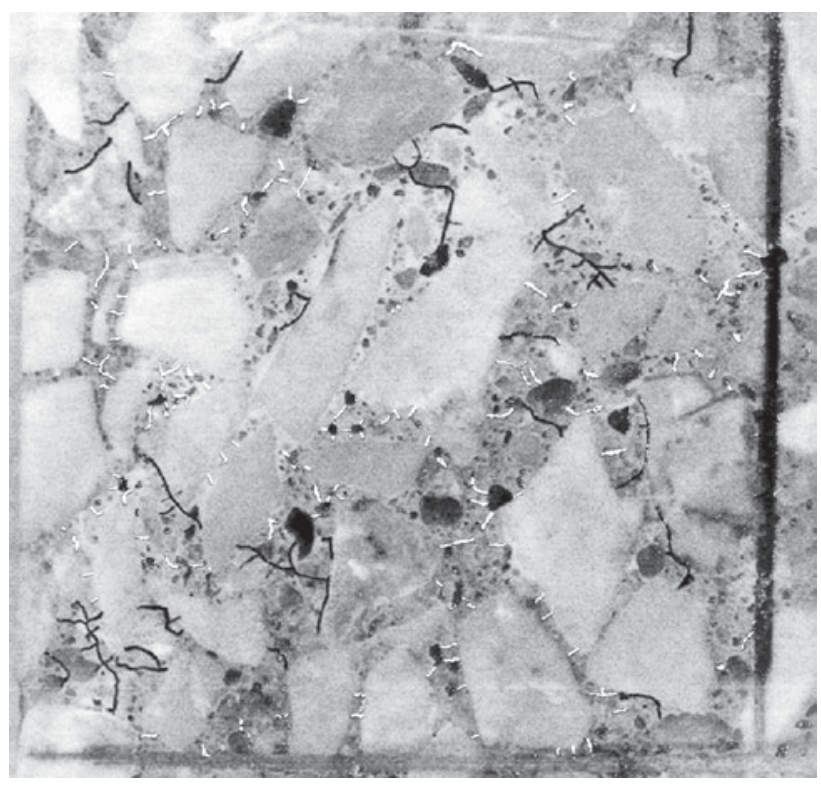

Figura 3. Microcracking in Uniaxial Tension. White lines: mortar cracks; black lines: combined cracks.

length of simple and combined cracks as failure is reached. The results also show a progressive increase in the percentage of the total length of Type II combined cracks in relation to Type I near failure, which is a sign of a more unstable progressive microcracking. This instability in the crack growth mechanism is directly reflected in the stress-strain diagram of high-performance concrete. This relationship is 
no longer linear at high levels of straining. Several studies ${ }^{6,11,12}$ have observed this same finding.

In relation to uniaxial tension and biaxial tension-compression stresses, the analysis of the microcracking process shows a different pattern. Not only are the percentages of simple and combined cracks constant as failure becomes eminent but also the percentages of Type I and Type II combined cracks. This is a sign of stable progressive cracking which resembles the behavior of a homogeneous material. Consequently the stress-strain relationships should also approach that of a homogeneous material, which is very well represented by the linearity in the stress-strain diagrams.

\section{Concluding Remarks}

1.The introduction of a principal tensile stress reduces substantially the ultimate compressive strength under biaxial tension-compression in relation to the uniaxial compressive strength. This difference in behavior has important design implications of HPC structures. An example would be in the shear design of reinforced concrete flexural elements.

2. Differently from NSC, the amount of bond and mortar cracks in HPC is almost equal prior to loading.

3. In uniaxial compression, the microcracking process at high levels of straining is more of an unstable progressive nature. Consequently, the stress-strain curve deviates significantly from linearity at high levels of stress. In uniaxial tension and biaxial tension-compression stress ratios, the cracking process is more of a stable progressive nature approaching that of a homogeneous material. Consequently, the stress-strain curve is almost linear up to failure.

\section{References}

1. American Concrete Institute, "State-of-the-Art Report on High Strength Concrete", Report by ACI Committee 363, reapproved in 1997.
2. Bazant, Z.P. "Concrete fracture models: testing and practice", Engineering Fracture Mechanics, v. 69, p. 165205, 2002.

3. Nemati, K.; Monteiro, P.; Scrivener, K. "Analysis of Compressive Stress-Induced Cracks in Concrete, ACI Materials Journal, v. 95, n. 5, p. 617-630, 1998.

4. Hilsdorf, H.K. "Die Bestimnung der Zweinchsigen Festkeit von Beton", Deutscher Ausschuss für Stahlbeton, Heft 173, Berlin, 1965.

5. Ouyang, C.; Landis, E.; Shah, S. "Damage Assessment in Concrete using Quantitative Acoustic Emission", ASCE Journal of Engineering Mechanics Division, v. 117, n. 11, p. 2681-2698, 1991.

6. Hsu, T.; Slate, F.; Sturman, G.; Winter, G. "Microcracking of Plain Concrete and the Shape of the Stress-Strain Curve", ACI Journal, v. 60, n. 14, p. 209-224, 1963.

7. Martz, H.; Schneberk, D.; Roberson, G.; Monteiro, P. "Computerized Tomography of Concrete, ACI Materials Journal, v. 90, n. 3, p. 259-264, 1993.

8. Nemati, K.; Monteiro, P.; Cook, N. "A New Method for Studying Stress-Induced Microcracks in Concrete, ASCE Journal of Materials in Civil Engineering, v. 10, n. 3, p. 128-134, 1998.

9. Calixto, J.M. "Microcracking of High-Strength Concrete Subjected to Biaxial Tension-Compression Stresses", Master's Thesis, The University of Texas at Austin, 1987.

10. Tasuji, M.; Slate, F.; Nilson, A. "Stress-Strain Response and Fracture of Concrete in Biaxial Loading", ACI Journal, v. 75, n. 7, p. 306-312, 1978.

11. Carrasquillo, R.; Nilson, A.; Slate, F. "Microcracking and Behavior of High-Strength Concrete Subjected to Short-Term Loading", ACI Journal, v. 78, n. 3, p. 179186, 1981.

12. Shah, S.; Sankar, R. "Internal Cracking and Strain Softening Response of Concrete Under Uniaxial Compression”, ACI Materials Journal, v. 84, n. 3, p. 200-212, 1987. 